\title{
O MOTOCICLISTA E A LEI: POR UMA RELAÇÃO SOCIOPOÉTICA DE (DES) CONSTRUÇÃO PARA A "VIDA" - UMA LINGUAGEM NO TRÂNSITO "
}

\author{
The motorcyclist and the law: for a sociopoetic relationship of (des) construction for "life" - a language in transit
}

\section{Francisco Renato Lima ${ }^{2}$}

\section{Antes, uma breve explicação...}

A leitura dos aforismos que apresento neste ensaio-teórico, pressupõe a compreensão do que esse tipo de escrita representa. Por isso, convido o leitor, a enveredar-se por esse caminho, a partir das palavras de Meneghetti (2011, p. 321), de quem compartilho o ponto de vista:

\begin{abstract}
"Quando brinco com minha gata, quem sabe se ela não está se divertindo mais comigo do que eu com ela?” (Montaigne, 2002, p. 3). Este é o espírito do ensaio-teórico, a relação permanente entre o sujeito e objeto, um vir-a-ser constituído pela interação da subjetividade com a objetividade dos envolvidos. Neste contexto, o ensaio, desde a época de Montaigne, "se tornou uma forma respeitável; sua novidade estava na louvação do eu. Sua razão de ser era a noção de que os pensamentos, sentimentos, incertezas, certezas e contradições de uma pessoa merecem divulgação e em seguida atenção de outras" (Boorstin, 1995, p. 697). Da época de Montaigne até a atualidade, os ensaios adquiriram diversas formas e formatos, assim como são utilizados para diversos fins: literários, filosóficos, científicos etc. Essas variações nas formas e formatos, assim como a multiplicidade nas suas utilizações, levam a concepções e usos equivocados desse estilo e forma de refletir a realidade. Diferente do método tradicional da ciência, em que a forma é considerada mais importante que o conteúdo, o ensaio requer sujeitos, ensaísta e leitor, capazes de avaliarem que a compreensão da realidade também ocorre de outras formas.

Este ensaio deve ser lido por sujeitos com espíritos livres de preconceitos, sem estarem dominados pelo formalismo da ciência. Aqui o leitor não encontrará a disposição formal de um estudo que segue a divisão e a lógica estabelecida pelas metodologias científicas tradicionais. No lugar do objetivo geral, dos objetivos específicos, da justificativa, da fundamentação teórica, da metodologia que define os critérios de coleta e análise de dados e da conclusão, no ensaio a orientação é dada não pela busca das respostas e afirmações verdadeiras, mas pelas perguntas que orientam os sujeitos para as reflexões mais profundas. Assim, respeitando a concepção original do que é ensaio, este necessita de leitores preparados para compreender a sua importância para a formação do
\end{abstract}

\footnotetext{
${ }^{1}$ Este texto é uma versão atualizada de algumas reflexões feitas na disciplina: 'Estágio Curricular Obrigatório IV: Práticas Pedagógicas em Instituições não Escolares', do curso de Licenciatura em Pedagogia da Faculdade Santo Agostinho (FSA), cursada no semestre 2012.2, sob a orientação da professora Me. Rosimar da Silva Feitosa Soares Costa. Na oportunidade, o campo de realização das atividades práticas da disciplina foi a Escola Piauiense de Trânsito, órgão subordinado ao Departamento Estadual de Trânsito do Piaú (DETRAN), daí o investimento na escrita desse texto.

Agradeço a querida amiga e grande incentivadora intelectual, profa. Me. Jovina da Silva, pela leitura e estímulo na ocasião da escrita deste texto.

2 Graduado em Pedagogia (FSA) e Letras - Português/Inglês (IESM). Mestre em Letras - Estudos da Linguagem (UFPI). Professor substituto da educação básica - SEDUC-PI. Professor de Leitura e Produção de Texto no Ensino Fundamental e Médio do Instituto Dom Barreto (IDB). Coordenador de disciplinas do Centro de Educação Aberta e a Distância da Universidade Federal do Piauí (CEAD/UFPI). Email: fcorenatolima@hotmail.com
} 
conhecimento na atualidade. Basta lembrar que o empirismo, o racionalismo, o positivismo e tantos outros conhecimentos que sustentam a base da ciência tradicional de hoje surgiram por meio de vários ensaios de pensadores e intelectuais. Logo, as perguntas fundamentais que orientam este ensaio são: que é e quais as características, como se dá a construção, quais os elementos presentes no movimento de construção, quais as relações entre o ensaio e a administração de um ensaio?

Para os leitores mais tradicionais, que esperam conclusões por meio de afirmações definitivas, a orientação é que cessem a leitura neste momento. As reflexões no decorrer do ensaio instigam os leitores a tirar suas próprias conclusões. Para aqueles que gostam de desafios e provocações que levam a livres reflexões e conclusões, a aventura começa agora. Da época de Montaigne até a atualidade, os ensaios tornaram-se importantes formas de geração de conhecimento. Várias são as áreas que os utilizam como forma: da ciência física à literatura, passando pela filosofia, pelas ciências sociais, pela química e pela biologia; o ensaio é forma que quebra a lógica esquemática e sistemática da ciência tradicional, sobretudo de natureza positivista. (Grifos Meus)

Então, cientes do ponto que fecundou esta escrita, enveredemo-nos por sua leitura!

\section{A leitura, então...}

Imersos em uma sociedade extremante polarizada e demarcada pelas relações de conflitos e disputas territoriais, o espaço do trânsito emerge como lugar-comum para o dualismo, a plurivocalidade de vozes e coexistência de sujeitos (pedestres e motoristas), vivenciando, muitas vezes, situações de confluência e entrechoque de egos, evidentes, inclusive, como fazem uso da linguagem nesse espaço, daí falar em uma linguagem no trânsito. Nesse trajeto, o encontro é inevitável, a relação é conflituosa e também inegável, por isso, buscam-se fugas ou desvios na luta pelo lugar privilegiado "na faixa", ultrapassando assim, os limites de respeito às regras de boa "vizinhança" nos espaços coletivos de convivência.

Nesse quadro, inserem-se principalmente os motociclistas, transportadores de histórias e aventuras, por "brechas" entre carros, muros e pedestres. "Velozes e furiosos" ${ }^{1}$, os motociclistas vão longe, driblam o caos da cidade grande e alcançam longas distâncias em curto período de tempo. Em contrapartida, o preço desta corrida pode ser muito caro, a própria Vida, o seu bem mais valioso e determinante de sua existência.

Discute-se, neste ensaio, a relação entre o motociclista e as leis de trânsito, a partir do conceito metodológico da sociopoética, que defende a coletividade e o respeito ao "outro", na desconstrução de pré-conceitos individualistas, frutos do paradigma newtoniano-cartesiano instaurado nas relações de convivência humana da sociedade contemporânea.

\footnotetext{
${ }^{1}$ Referencia direta ao filme, de título homônimo: VELOZES E FURIOSOS. Direção: Rob Cohen. Intérpretes: Van Diesel, Paul Walker, Michelle Rodriguez, Jordana Brewster. Roteiro: Gary Scott Thompson. Gênero: Ação. Duração: 106 minutos.
} 
O motociclista é todo aquele sujeito que utiliza o transporte automotivo de duas rodas para locomover-se, seja por motivos de lazer, esporte, diversão ou mesmo, como meio de trabalho. No contexto de uma sociedade globalizada, as motos tornam-se instrumento ambulante, de histórias de vidas, que se entrecruzam e se fundem, porém, muitas vezes, pela pressa e vontade de chegar ao destino, driblam o caos e (des) constroem vidas.

Em cima de duas rodas, o motociclista ultrapassa, não somente, os limites espaciais e temporais, mas também, os limites da lei, que estão expressos nos dispositivos legais do trânsito, especificamente no Código de Trânsito Brasileiro (CTB), Lei 9.503 de 23/09/1997, que estabelece as normas que disciplinam e orientam todas as atividades neste espaço em vias abertas à circulação. "O trânsito, em condições seguras, é um direito de todos...” (CTB, art. $\left.1^{\circ} \int 2\right)$.

A respeito de trânsito, o CTB, em seu artigo $1^{\circ}, \llbracket 1^{\circ}$ diz que: "Considera-se trânsito a utilização das vias por pessoas, veículos e animais, isolados ou em grupos, conduzidos ou não, para fins de circulação, parada, estacionamento e operação de cargas e descargas".

O sistema social da atualidade urge por agilidade, praticidade e rapidez na movimentação e circulação entre as pessoas. O trânsito torna-se o espaço vivo da guerra, brigas (marcadas por expressivos usos da língua, com termos considerados chulos e agressivos), tensões, confrontos e do desequilíbrio entre carros, motos e pedestres, ocasionando um problema social, com sérias consequências: os acidentes, que na maioria são protagonizados por motociclistas. Pena, que nesse roteiro, os protagonistas acabam morrendo ou matando com muita frequência, dividindo opiniões entre ser o "mocinho" ou o "vilão" da história, que não apresenta um final feliz.

A falta de conhecimento, responsabilidade e fiscalização das leis de trânsito, faz com que os acidentes alcancem índices alarmantes, que depõem contra a má conduta e desrespeito a uma relação sociopoética para a construção da vida. Os dados da realidade são aterradores. As estatísticas apontam para o número exorbitante de acidentes fatais, a maioria deles envolvendo diretamente motociclistas. Por ano, contabilizam-se dois milhões de vítimas fatais e mais cinquenta milhões ficam feridas, muitas delas, com sequelas definitivas.

O quadro numérico desta realidade é apontado pela Organização das Nações Unidas (ONU), em 2011, que assim esmiúça os resultados das ações cometidas no trânsito: 2 milhões no Planeta; 55 mil mortos no Brasil; 1006 mortos no Piauí; e 161 mortos em Teresina. Tais dados amedrontam toda a sociedade, a ponto da Organização Mundial de Saúde (OMS), apontá-los como questão de saúde pública, exigindo de todos - autoridades, empresas públicas e privadas, organizações sociais, meios de comunicação e o próprio cidadão - atitudes firmes e definitivas.

Esta situação fez com que em 2003, a RoadPeace, uma organização de caridade do Reino Unido em prol das vítimas de acidentes rodoviários, instituísse o Dia Mundial em Memória das 
Vítimas do Trânsito, realizado no terceiro domingo de novembro de cada ano, como uma oportunidade de aumentar a consciência pública em relação ao custo dos acidentes rodoviários para as comunidades, e enfatizar a necessidade de começar e promover esforços para controlar este grave problema de saúde e desenvolvimento de apoio às vítimas.

A reflexão pública é um ato de reconhecimento. A comemoração pública não se destina apenas às vítimas, mas também, os familiares, quando os Estados da federação, tem a oportunidade de mostrar, que a perda é de todos e que o sofrimento é compartilhado.

A dualidade motociclista e lei constrói-se na relação díspara de desrespeito, enfrentamento e negligência dos condutores. Assim como em matéria de lei no Brasil, no que tange a este caso não seria diferente, há um descompasso entre o "dito" e o "feito". Os motociclistas não seguem as determinações legais, e na maior velocidade, ultrapassam o sinal, lesando vidas pelo caminho, interrompendo histórias humanas e muitas vezes, deixando sua vida nas 'estradas'.

As leis têm repercussão nacional e buscam organizar e regulamentar a convivência no trânsito, de forma a flexibilizar e orientar a locomoção de todos, portanto, os usuários não podem alegar desconhecimento destas em sua defesa, já que a legislação é clara ao atribuir como responsabilidade individual, os atos praticados em (des) acordo as regras de trânsito.

Ao 'passarem por cima' dos limites da lei, além de colocarem em riscos suas vidas e a dos outros, contribuem para uma construção social baseada na supervalorização do egoísmo, do individualismo, que desconhece e desrespeita o "outro". Este "outro" é o motorista, o pedestre ou o motociclista ao lado, que também busca inserir-se nesse mesmo espaço: o trânsito. $\mathrm{O}$ individualismo acirrado, nega o coletivismo e faz com que o sujeito não enxergue o outro, dando vida ao estranhamento e a negação ao seu semelhante.

A impossibilidade de convivência coletiva no trânsito em situações-limites impostas pela desordem cotidiana, faz emergir o conceito metodológico de sociopoética, a qual este texto apoia-se, numa perspectiva de romper com paradigmas do racionalismo técnico e unilateral nas relações humanas, buscando criar novos maneiras de problematizar a vida. No espaço do trânsito é preciso reconhecer-se como próximos, ainda que sejam singulares, pela " [...] diferença de cada voz, a tessitura de cada instrumento, o timbre de cada canto, riso ou choro [...] Sendo cada pessoa constituída de várias vozes, e atravessando cada voz, várias pessoas" (GAUTHIER; SANTOS, 1996, p. 53), mesmo que haja diferentes “[...] culturas, no plural, entendidas como as maneiras múltiplas e em contínua reconstituição [...] Se há fatores e valores que os aglutinam há questões que permanentemente os separam e fragmentam" (OLIVEIRA, 2000, p. 12) e assim, emparelhar 
vozes, de modo interativo e responsivo, fruto do respeito coletivo no espaço coletivo de convivência.

Para referir a tema, ainda não corrente na literatura científica, tão pouco na linguagem cotidiana, recorre-se a um conceito específico de Sociopoética, nas palavras de Gauthier (1999, p. 50), quando assim expressa: “[...] aquela trilha nunca pré-determinada, aberta ao acaso e ao inesperado. [...] Aberta à criatividade do grupo e dos indivíduos, aberta à poética da vida". "Ela é uma passagem obrigatória para quem quer transformar as práticas sociais, por paradoxalmente não visar à transformação social e ainda menos à conscientização, e sim ao conhecimento do inconsciente, através do descobrimento das Américas (negras, brancas, indígenas e mestiças) do pensamento [...]" (2003, p. 12).

Dessa forma, no espaço do trânsito, almeja-se que esse construto se viabilize pela relação de igualdade e democracia, respeito às regras legais e de convivência social entre veículos e pedestres, que estes possam construir a natureza da cidadania, pelo respeito ao outro, o diálogo como forma de solução de conflitos, a coletividade, a associação entre os pares e a heterogeneidade de pensamentos, de sujeitos que buscam conhecer o outro, como forma de conhecerem-se a si mesmos, como válvulas de vida na esfera global, construindo e sendo, ao mesmo tempo, construtores de uma outra linguagem no trânsito: a da tolerância e do respeito mútuo, verbalizada por palavras de compreensão e atitude responsiva e dialógica de linguagem (BAKHTIN, 2009 [1929] / 2011 [1979]).

Das implicaturas legais às de natureza vital, em vistas aos diversos acontecimentos catastróficos que intranquilizam a sociedade, os acidentes de trânsito com vítimas fatais, encurtam caminhos e destroem vidas. É urgente, portanto, acender uma luz de alerta - mais do que apenas os faróis - para toda a sociedade, no engajamento social, lutando por medidas interventivas e que sarem às feridas abertas pela falta de freio nas estradas. Precisa-se rever os modos de pensar e agir no trânsito e o respeito às leis que o regem, para a reconstrução e estruturação da natureza das relações entre os sujeitos, e a possível alusão a uma relação sociopoética de (des) construção para a "vida", metáfora que delineou toda esta escrita. 


\section{REFERÊNCIAS}

BAKHTIN, Mikhail (VOLOCHINOV, Valentin Nikolaevich). Marxismo e filosofia da linguagem. Tradução Michel Lahud e Yara Frateschi Vieira. 13. ed. São Paulo: Hucitec, 2009. [1929].

. Estética da criação verbal. Tradução Paulo Bezerra. 6. ed. São Paulo: Martins Fontes, 2011. [1979].

CÓDIGO DE TRANSITO BRASILEIRO - Lei n $^{\circ}$ 9.503, de 23 de setembro de 1997 (Portaria n ${ }^{\circ}$ 147/09).

DIA MUNDIAL EM MEMÓRIA DAS VÍTIMAS DO TRÂNSITO. Disponível em: < http://www.detran.pi.gov.br >. Acesso em: 03 dez. 2012.

GAUTHIER, Jacques. Sociopoética: encontro entre arte, ciência e democracia na pesquisa em ciências humanas e sociais, enfermagem e educação. Rio de Janeiro: Ed. Escola Anna Nery/UFRJ, 1999.

; SANTOS, Iraci dos. A Socio-Poética: fundamentos teóricos, técnicas diferenciadas de pesquisa, vivência. Rio de Janeiro: UERJ/DEPEXT/NAPE, 1996.

Notícias do rodapé do nascimento da sociopoética. Mimeografado, 2003.

MENEGHETTI, Francis Kanashiro. O que é um Ensaio-Teórico? RAC: Revista de Administração Contemporânea (Online), Curitiba, v. 15, n. 2, pp. 320-332, Mar./Abr. 2011. Disponível em: < http://www.scielo.br/pdf/rac/v15n2/v15n2a10.pdf >. Acesso em: 03 jun. 2017.

OLIVEIRA, Maria V. A. de S. C. Educação Popular em Saúde para além das palavras - um encontro com o sentir. In: RODRIGUES, Luiz Dias; VASCONCELOS, Eymard Mourão. Novas configurações em movimentos sociais: vozes do Nordeste. João Pessoa: Ed Universitária, 2000. 